simply as a consequence of their great inherent velocity, the theory becomes admirably fitted to strengthen the views of Olbers, Zöllner and Bredichin with regard to the nature and the origin of the repulsive force acting upon the cometary matter. But the introduction of Maxwell's pressure of light gives rise to a number of difficulties which, as Prof. Arrhenius abundantly shows, can only be overcome by arbitrary and unwarranted assumptions.

I shall take an early opportunity of demonstrating the superiority of Zöllner's theory over the one which now claims to "sweep the astronomical horizon of so many mysteries."

Royal Observatory, Edinburgh.

J. Halm.

Stopping down the Lens of the Human Eye.

MAY I be permitted to direct Mr. Wm. Andrews' attention to the fact that his experiment in "stopping down " the lens of the eye involves exactly the same principle as "orthoptics," of which every rifle-shot will have had experience.

The "orthoptic" consists of a round hole in a black disc, which replaces the lens of a pair of spectacles. The hole is generally adjustable in size, to suit varying conditions of light. The purpose of the orthoptic is to increase the depth of focus, enabling both back and fore sights and the target to be in sharp focus together. Persons with naturally large pupils will, as a rule, notice the effect more strongly.

H. Bliss. May 9.

IT may interest your readers to know that the principle referred to, under the above heading, in your issue of May 8 was adopted, a great many years ago, by the late Lord Sherbrooke, whose sight I believe was very defective. I remember seeing; about the middle of the seventies of the last century, at an exhibition of physical apparatus at South Kensington, a pair of spectacles which were said to have been invented by him for his own use. They consisted of two convex metal cups, closely resembling in shape and size the bowl of an ordinary tea-spoon. In the centre of each cup was a small pin-hole, which was the only aperture through which light could enter; and the two cups were fastened together by an elastic string, evidently intended to go over the head. The invention impressed me at the time as a remarkable example of scientific skill combined with great simplicity of contrivance.

Gerald Molloy.

The Evolution of Snails in the Bahama Islands.

IT seems desirable to call the attention of evolutionists to Dr. H. A. Pilsbry's monograph of the genus Cerion - (or Strophia), just published in the "Manual of Conchology." The facts presented are most of them not new, but all that is known is set forth in great detail, with an abundance of excellent figures. Cerion is a genus of rather large cylindrical landshells, for the most part inhabiting the Bahamas and Cuba. It has split up into innumerable local species and races, I34 of which are recognised as sufficiently distinct to bear names. Not only do even the smallest islands or "keys" produce distinct species, but frequently one small island will have two or more different forms inhabiting different parts, and sometimes a distinct race will occupy a very small area, surrounded on all sides by another type. The problem of the differentiation of the Achatinellidæ in the Hawaiian Islands is complicated by the complexity of their environment; but here in the Bahamas we have differentiation just as marked, with an environment-small sandy islands with palms and low bushes-as simple as we are likely to find anywhere. It would therefore seem that an ex. cellent opportunity lies before some student of evolution to investigate exhaustively the local species and races of these Bahama snails, and determine what causes have brought about the known results. Colonies could be taken to new localities, and watched from year to year to see whether they became modified. The food and moisture conditions might be altered, and the results observed. The exact conditions surrounding each distinct form might be studied and described. Thus it might be determined whether the differentiation was the result of natural selection or has taken place independently of it. Such an investigation would be delightful work for some enthusiastic naturalist, especially with such an excellent guide in hand as Dr. Pilsbry has supplied.

T. D. A. Cockereli.

East LaS Vegas, New Mexico, U.S.A., April 26. NO. I 698 , vOL. 667
Retention of Leaves by Deciduous Trees.

THE retention of leaves by beechen hedges referred to by your correspondent in NATURE, April ro, is by no means confined to those on elevated ground. It may commonly be observed in hedges of this tree whatever their situation. In Northumberland the beech is not infrequently used as a hedge, and always retains its leaves throughout the winter. Young beech trees also frequently retain their leaves, and by no means always in exposed situations. Indeed, the examples I have myself seen have been much more frequently in sheltered spots, as in plantations of older trees.

Nor is this phenomenon of deciduous trees retaining their leaves under certain conditions confined to the beech. It is, perhaps, equally common in the oak. Young oak trees in plantations may often be seen in the spring covered with brown and withered leaves. Larger trees may also sometimes be seen retaining the leaves on some of the lower branches, while the upper ones are bare. Travelling from Eastbourne to Victoria, soon after reading the above communication in NATURE, I noticed hundreds of young oaks covered with withered leaves. None of these were in elevated or exposed situations. Indeed, I am inclined to suggest, as an inference from the above facts, that it is rather the protection enjoyed by the trees which enables them to retain their leaves. In the one case the lesser height of the tree, and in the other the close intergrowth of the hedge, gives the wind less power to strip off the leaves. We can hardly consider that there is here a "protective device," unless on the part of the gardener who sets a beechen hedge to shelter his plants.

13 Vicarage Drive, Eastbourne, May 3.

WiTH regard to the interesting communications concerning the retention of their leaves by young beeches, I beg to forward another possible solution. The beech is a "frost-tender" species, and early frosts, which would not rise high enough to affect large trees, would freeze the leaves of "small young" trees, thus preventing the formation of the abscission layer of cork at the base of the petiole. In such a case there is no reason why the leaves should fall off for a considerable time.

Leaves killed before the formation of this layer remain on the branch for an indefinite time, of which phenomenon pea-sticks cut in full leaf may serve as an example. $\quad$ P. T.

May 10.

\section{THE RECENT VOLCANIC ERUPTIONS IN THE WEST INDIES.}

NEWS of the terrible volcanic eruption in Martinique reached this country on Thursday last, and the details which have since become known have shown that an appalling disaster has occurred. St. Pierre, the chief commercial centre of the island, has been totally destroyed, and about thirty thousand people have perished. The eruption of Mont Pelée began on the night of Saturday, May 3, when large quantities of scoriæ and volcanic ash were thrown into the surround. ing country. On Monday, May 5, a stream of lava is reported to have rushed down the side of Mont Pelée, following the dry bed of a torrent, and reaching the sea, five miles from the mountain, in three minutes. When the stream met the sea the water receded 300 feet on the west coast, returning with greater strength in a large wave.

Two days later, on May 8, a similar torrent of incandescent lava engulfed the town of St. Pierre. The following telegram describing the calamity was received at Paris from Fort de France on May II, and was published in Monday's Times.

"The town of St. Pierre was destroyed on the 8 th about 8 a.m. A terrible torrent of incandescent lava, from Mont Pelée, a volcano a few kilometres from the town, accompanied by a shower of fire, in a few seconds covered the town, and an immense furnace extended over the neighbouring coast, thus forming a line of fire from the village of Carbet to the town of Prêcheur. The effects of this volcanic torrent were felt as far as 